\title{
Some effects of mucopolysaccharide stains on platelet aggregation
}

\author{
J. R. O'BRIEN \\ From the Portsmouth and Isle of Wight Area Pathology Service, St Mary's General Hospital, Portsmouth
}

SYNOPSIS Five mucopolysaccharide stains inhibit platelet aggregation induced by several aggregating agents: with two stains inhibition is competitive. Alcian blue, $0.05 \mathrm{mg} / \mathrm{ml}$, added to platelet-rich plasma potentiates ADP-induced aggregation. Alcian blue, $0.5 \mathrm{mg} / \mathrm{ml}$, itself produces platelet aggregation, probably causing the release reaction. Three of these stains produce aggregation of red cells. They also bind heparin, and so may influence heparinneutralizing sites (platelet factor 4) and probably the charge on the platelet membrane. The only known common factor to these stains is their ability to bind onto the mucopolysaccharides. It is suggested that when platelets are 'stained' the surface mucopolysaccharide is altered and that this alteration can influence platelet aggregation.

Platelet adhesion and aggregation undoubtedly play a central role in haemostasis, but the nature of the change in the platelet membrane when it becomes 'sticky' is not established. This communication describes a new way of influencing platelet aggregation which may give a clue to the nature of this change.

Only one other report, in 1909 , claims that mucopolysaccharide stains have a physiological effect: brilliant cresyl blue inhibited clot retraction (Achard and Aynard, 1909) which is now known to depend on normal platelet function, and the addition of high concentrations of cresyl blue have been reported to influence platelet aggregation (Muir and Mustard, 1967). Mucopolysaccharides have been reported in the surface coat of the platelets (Behnke, 1968; Nakao and Angrist, 1968; French, Adams, and Sheppard, 1970) and so they may be involved in surface phenomena (Shirasawa and Chandler, 1969; White, 1970). One of the most important of these phenomena is the development of stickiness. Mucopolysaccharide stains used in light or electron microscopy (Luft, 1966; Tice and Barrnett, 1965; Scott and Willett, 1966) have been shown to precipitate anionic mucopolysaccharides in vitro (Walton and Ricketts, 1954).

Received for publication 22 October 1970.
Thus their effect on platelet aggregation was tested since aggregability must reflect the membrane change here referred to as the development of 'stickiness'.

\section{Methods and Materials}

Fresh human citrated $(0.32 \%)$ platelet-rich plasma was prepared and $2 \mathrm{ml}$ aliquots were stirred in the aggregometer cuvette (O'Brien, Heywood, and Heady, 1966) with the addition, after two minutes at $37^{\circ} \mathrm{C}$, of $0.1 \mathrm{ml}$ of saline buffered with barbitone to $\mathrm{pH} \mathbf{7 \cdot 3}$ alone (the control) or saline containing sufficient stain to give the final concentrations quoted; if the added stain did not cause aggregation, then $0.1 \mathrm{ml}$ of an aggregating agent was added. The light transmission of the platelet-rich plasma was continuously monitored and a tracing was obtained that recorded the degree of aggregation-a deflection down-or disaggregation against time. When strongly coloured stains were added the electrical system had to be adjusted and so an equivalent filter was introduced into the light path of the controls. All results were repeatedly checked. The concentrations quoted are only 
approximate because different plasmas gave Results slightly differing results.

The lanthanum and ruthenium salts were obtained from British Drug Houses and all the other stains from G. T. Gurr Ltd. The normal aggregating agents were adenosine diphosphate and a tendon extract called collagen here (Sigma), human thrombin (Medical Research Council, Elstree), and adrenaline hydrogen tartrate (British Drug Houses).

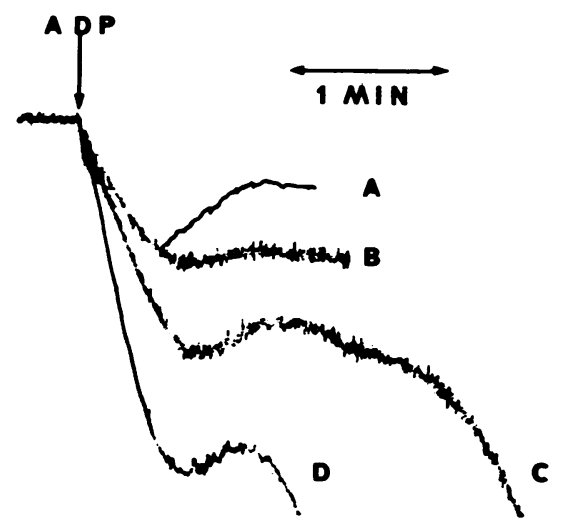

Fig. 1 Alcian blue was added to platelet-rich plasma. The final concentrations were: A saline only (the control); B $0.005 \mathrm{mg} / \mathrm{ml} ; \mathrm{C} 0.025 \mathrm{mg} / \mathrm{ml} ; \mathrm{D} 0.05$ $\mathrm{mg} / \mathrm{ml}$. Two minutes later the tracings were begun and ADP 2.5 $\mu M$ was added at the arrow.

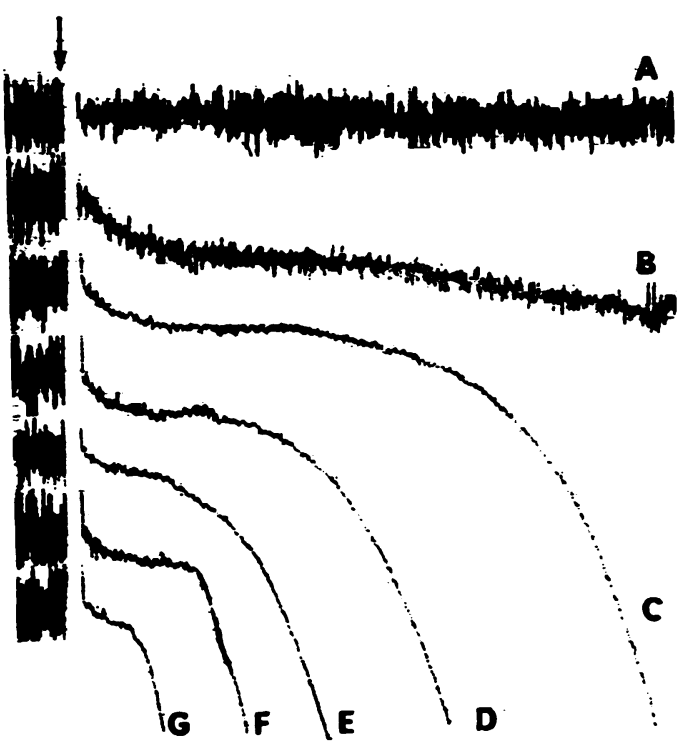

Fig. 2 At the arrow alcian blue was added to stirred platelet-rich plasma at $37^{\circ}$. The final concentrations were: A saline only (the control); B $0.05 \mathrm{mg} / \mathrm{ml}$; C $0.12 \mathrm{mg} / \mathrm{ml} ; \mathrm{D} 0.19 \mathrm{mg} / \mathrm{ml} ; \mathrm{E} 0.22 \mathrm{mg} / \mathrm{ml}$; F $0.25 \mathrm{mg} / \mathrm{ml} ; \mathrm{G} 0.5 \mathrm{mg} / \mathrm{ml}$.

ALCIAN BLUE

Three different effects were demonstrated depend-으. ing on the strength of alcian blue used.

1 Alcian blue, 0.5 to $0.005 \mathrm{mg} / \mathrm{ml}$, when added $\stackrel{5}{=}$ to platelet-rich plasma did not itself cause aggre-읃 gation, but if ADP or another aggregating agent $\overline{\text {. }}$. (thrombin, adrenaline, or collagen) was then added the expected response was markedly in- $\stackrel{\mathbb{Q}}{\varrho}$ creased (Fig. 1). On occasion this potentiatinges effect was demonstrable even at alcian blue 0.5 $\mu \mathrm{g} / \mathrm{ml}$ or $0.38 \mu \mathrm{M}$.

2 Alcian blue, 0.2 to $0.6 \mathrm{mg} / \mathrm{ml}$, added to $\overrightarrow{\vec{\omega}}$ platelet-rich plasma, itself caused a dose-dependent wave of aggregation after an initial delay (Fig. 2).

3 Higher concentrations of alcian blue causedin less aggregation (Fig. 3) until finally at aboutco $4 \mathrm{mg} / \mathrm{ml}$ no aggregation occurred and then the addition of strong ADP or other aggregation + agent had no effect. Thus alcian blue had in-? hibited the response to ADP.

Alcian-blue aggregation was inhibited by the prior addition of EDTA. If a critical low strength of alcian blue giving a weak wave of aggregationz

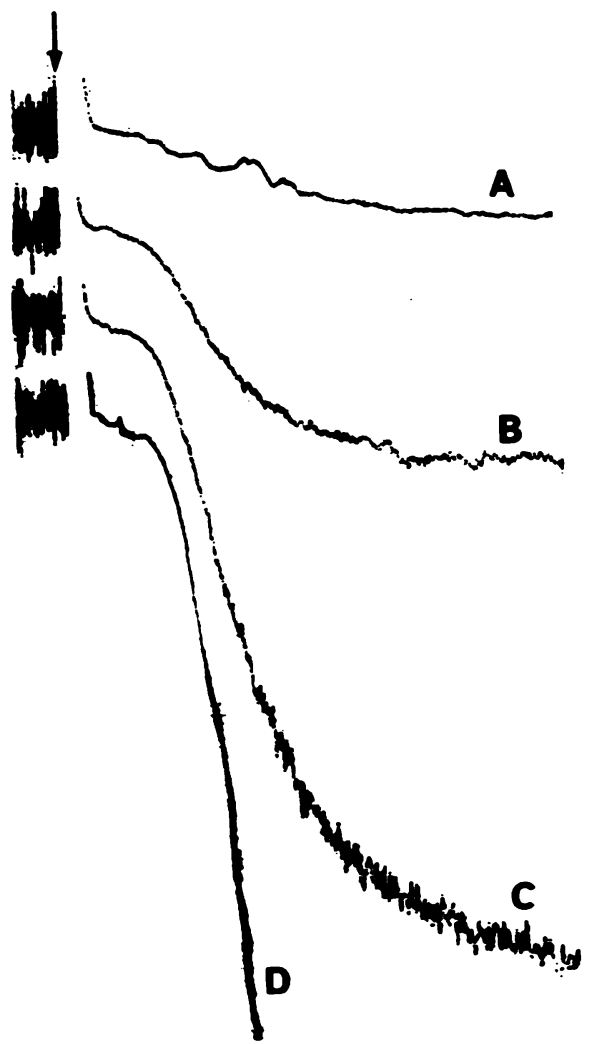

Fig. 3 At the arrow alcian blue was added to stirred platelet-rich plasma at $37^{\circ}$. The final concentrations were: A $4 \mathrm{mg} / \mathrm{ml}$; B $2 \mathrm{mg} / \mathrm{ml}$; C $1 \mathrm{mg} / \mathrm{ml}$; D 0.5 $m g / m l$. 
was selected and adenosine $5 \mathrm{mM}$ added before the alcian blue, then aggregation was inhibited; aggregation by stronger alcian blue was hardly affected by adenosine at this strength. The aggregation tracings obtained with alcian blue suggest a release reaction. Accordingly $0.2 \mathrm{ml}$ aliquots were taken one minute after the addition of 0.5 $\mathrm{mg} / \mathrm{ml}$ alcian blue either to platelet-rich or to platelet-poor plasma. The aliquots from plateletrich plasma added to substrate platelet-rich plasma caused aggregation; the aliquots from platelet-poor plasma did not. Thus an aggregating agent had been released. Preincubation of plateletrich plasma with aspirin $5 \mathrm{mM}$ or from a donor taken hours after he had eaten aspirin did not prevent subsequent alcian blue-induced aggregation. Alcian blue added to platelet-poor plasma had no effect. Alcian green added to platelet-rich plasma gave results similar to those with alcian blue.

\section{LANTHANUM SALTS}

The addition of lanthanum nitrate, $7.5 \mathrm{mg} / \mathrm{ml}$, to platelet-rich plasma profoundly decreased aggregation induced by strong ADP, and at all attainable lanthanum concentrations inhibition was shown to be competitive. By adding ADP alone in increasing amounts a family of aggregation curves is obtained. Increasing concentrations of lanthanum from $0.1 \mathrm{mg} / \mathrm{ml}$ to $2 \cdot 0 \mathrm{mg} / \mathrm{ml}$ added before strong ADP caused increasing inhibition and gave an exactly similar family of curves (Fig. 4). This type of competitive inhibition was demonstrable over a wide range of ADP concentrations $(0.5 \mu \mathrm{M}$ to $0.5 \mathrm{mM})$, and with lanthanum from $7 \mathrm{mg} / \mathrm{ml}$ to $0 \cdot 1 \mathrm{mg} / \mathrm{ml}$ (Fig. 5). No lanthanum concentration itself caused aggregation or enhanced ADP-induced aggregation. Aggregation induced by thrombin, adrenaline, and collagen was similarly and competitively inhibited by the various concentrations of lanthanum. Lanthanum chloride was as effective as lanthanum nitrate.

\section{RUTHENIUM SALTS}

Normally aggregation induced by all the usual aggregating agents mentioned above was completely inhibited by $5 \mathrm{mg} / \mathrm{ml}$ of ruthenium red or of the trichloride. Lower concentrations of ruthenium $(0.5$ to $0.05 \mathrm{mg} / \mathrm{ml})$ gave results with the four aggregating agents which were exactly parallel to those using lanthanum, and inhibition was again shown to be competitive (Fig. 6).

TOLUIDINE BLUE AND BRILLIANT CRESYL B L U E

At concentrations of $0.1 \mathrm{mg} / \mathrm{ml}$ and $0.2 \mathrm{mg} / \mathrm{ml}$ respectively these dyes inhibited all aggregation, and at lower concentrations aggregation was

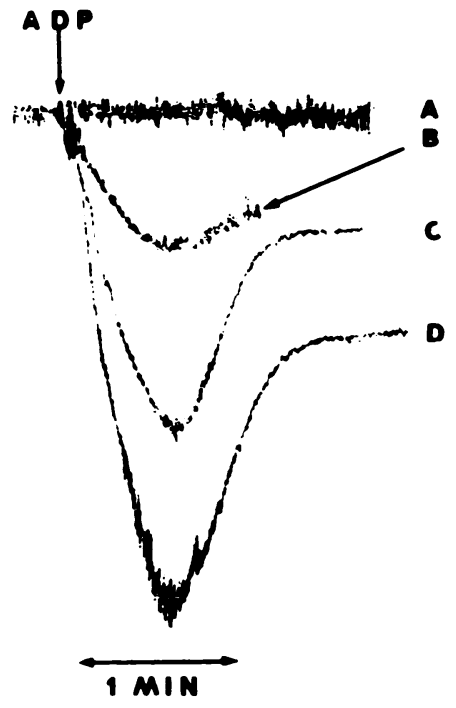

Fig. 4 Lanthanum nitrate was added to samples of platelet-rich plasma to achieve the following final concentrations: A $7.8 \mathrm{mg} / \mathrm{ml}$; B $2.6 \mathrm{mg} / \mathrm{ml}$; C 0.26 $\mathrm{mg} / \mathrm{ml} ; \mathrm{D}$ saline only (the control). Two minutes later $A D P \quad 0.5 \mu M$ was added.

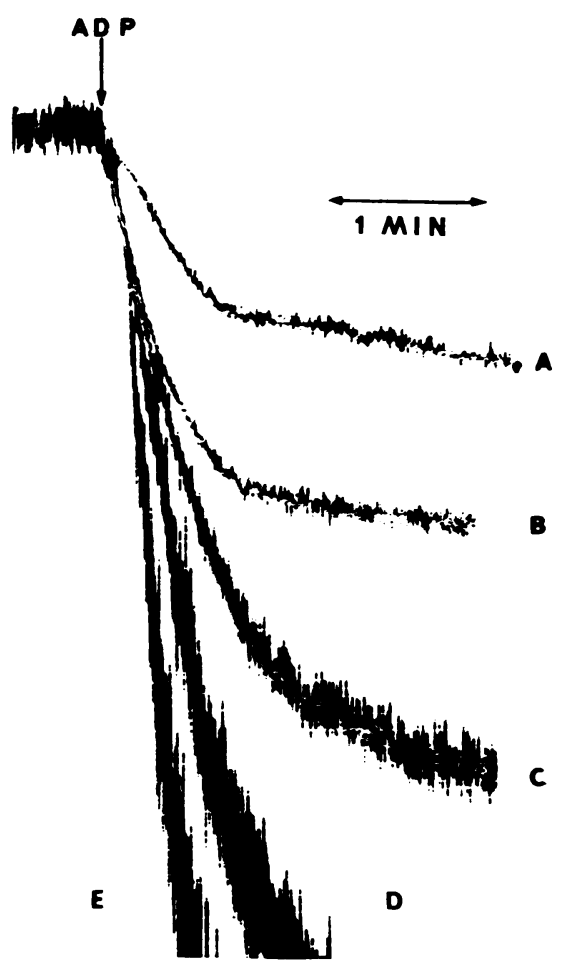

Fig. 5 Lanthanum nitrate was added to platelet-richo plasma to achieve the following final concentrations: A $7.5 \mathrm{mg} / \mathrm{ml}$; B $6.2 \mathrm{mg} / \mathrm{ml}$; C $5 \mathrm{mg} / \mathrm{ml}$; D 2.5 $\mathrm{mg} / \mathrm{ml}$; E saline only (the control). Two minutes later ADP $5 \mu M$ was added. 


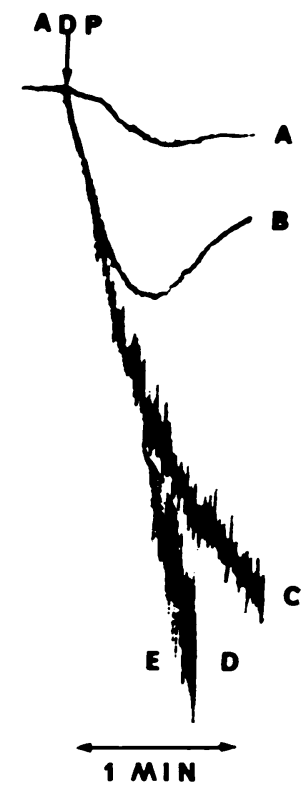

Fig. 6 Ruthenium red was added to platelet-rich plasma to achieve the following final concentrations: A $5 \mathrm{mg} / \mathrm{ml}$; B $0.5 \mathrm{mg} / \mathrm{ml}$; C $0.05 \mathrm{mg} / \mathrm{ml}$; D 0.005 $\mathrm{mg} / \mathrm{ml}$, which is superimposed on $\mathrm{E}$, the control. At the arrow $A D P 10 \mu M$ was added.

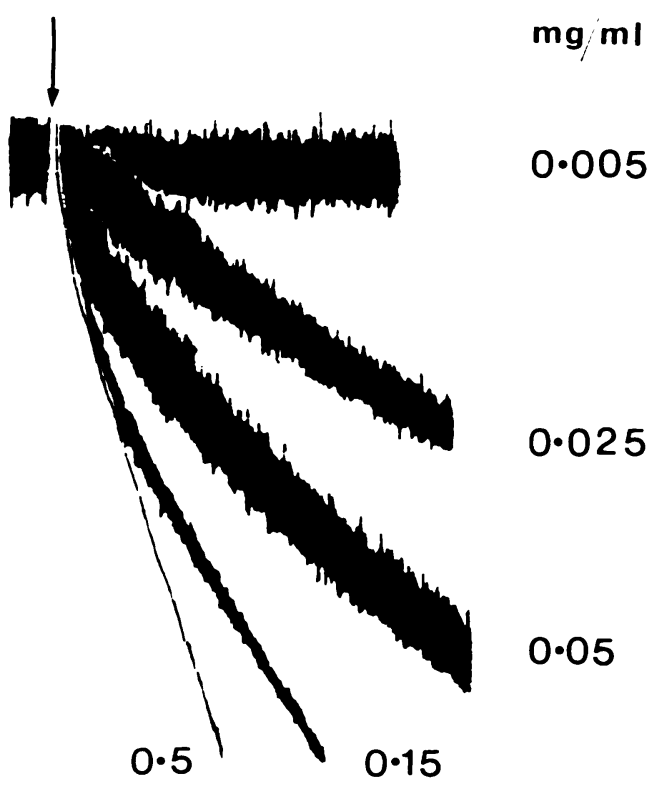

Fig. 7 Washed human red cells, 100,000/cmm, in saline were stirred in the aggregometer. At the arrow alcian blue as added in sufficient strength to produce the final concentration shown. partially inhibited but the curves obtaineff differed to some extent from those obtained byo simply decreasing the concentration of the aggregating agent.

EFFECT OF THESE STAINS ON RED CELLS Human red cells were obtained from citrated blood and washed three times in barbitone $-\frac{\bar{T}}{-}$ buffered saline. These were then suspended in buffered saline at a concentration of $100,000 / \mathrm{cmm}$ in the platelet aggregometer. The addition of three stains at varying and critical concentrations caused immediate aggregation which usually $\vec{\omega}$ proceeded linearly (Table and Fig. 7). The addition of plasma or serum prevented aggre $\frac{\widehat{\Omega}}{0}$ gation.

EFFECT OF THESE STAINS ON HEPARIN Substrate platelet-poor plasma, $0.1 \mathrm{ml}$, and $0 \cdot 2$ ? $\mathrm{ml}$ saline were clotted by adding $0.1 \mathrm{ml}$ thrombin$(10 \mathrm{U} / \mathrm{ml})$ which gave a clotting time of about 10 seconds. Heparin $0.1 \mathrm{ml}(0.4 \mathrm{U} / \mathrm{ml})$ was then added in place of $0.1 \mathrm{ml}$ of saline and this gaves a clotting time of 35 seconds. The addition of stains in place of the last $0.1 \mathrm{ml}$ of saline caused $\overline{ }$ a return of the clotting time to 10 to 15 seconds. The order of addition was plasma, stain, heparin; and thrombin (Table). Accordingly it is concluded that these stains can neutralize heparin.

\section{Discussion}

The findings are clear cut, but the interpretation and conclusions from them are at present specu lative and further studies are in progress. This ${ }^{\omega}$ does, however, seem to be the first occasion known to the author when stains have been usece in an attempt both to identify the type of molecule involved in a physiological process and to modify this process. At least a new group of compounds influencing platelet aggregation has been found. $\overrightarrow{\mathbb{D}}$

The five stains, selected only because they allegedly stain mucopolysaccharides, all inhibie platelet aggregation however induced: and two do so in a precise competitive manner. This effect might be due to the stains inactivating ADP but this suggestion is incompatible witho 
the potentiating effect of alcian blue on ADPinduced aggregation. The only common effect of these five very different compounds is that they stain mucopolysaccharide which has been shown to be present on the platelet surface. Thus it seems likely that all the stains, even at physiological ion concentration and $p \mathrm{H}$, alter the platelet membrane mucopolysaccharide and that this interferes with aggregation.

The different effects of alcian blue at lower concentration must have another explanation. Alcian blue can potentiate the effects of the usual aggregating agents. This suggests that it acts on the same metabolic pathway normally involved in the development of stickiness. Aggregation induced by weak alcian blue is inhibited by adenosine. Thus intrinsic ADP may be involved, and the following findings all suggest that the normal release mechanism occurs: the delay before aggregation begins, the kinetics of aggregation, ie, the increasing rate of aggregation, the release of an aggregating agent, and the calcium dependency. If release occurs it is unexpected that aspirin has no inhibitory effect. How alcian blue could induce release is unknown. An alternative suggestion, possible but unlikely, is that 'staining' the platelet surface results in a relatively simple and unphysiological change in charge which results in aggregation and that release follows as a secondary phenomenon.

There may be some similarity between staininduced aggregation of red cells and platelets since three of the stains aggregate both cell types. If the red cell membrane contains mucopolysaccharides this may be changed when exposed to the stain, thus facilitating aggregation. This change is probably a decrease in surface charge. However, there are important differences between the effect of stains on red cells and platelets. Alcian blue and two other stains aggregate red cells; only alcian blue aggregates platelets. The addition of plasma to red cells inhibits aggregation: platelets in plasma can aggregate. It seems probable that an electrostatic charge is involved in these phenomena. A platelet (and a red cell) carries a negative charge and this is decreased on adding ADP (Seaman and Vassar, 1966) when it becomes sticky. At the same time platelet factor 4 (heparin-neutralizing activity) develops on the membrane (O'Brien, Finch, and Clark, $1970)$ and this must carry a positive charge. The cationic stains are attracted to heparin and to acidic mucopolysaccharides (Scott and Willett $\overline{\overline{5}}$ 1966). Presumably a reduction of the platelet-0 negative charge could cause aggregation, bu绾 with more stain a reversal of charge could lead to. inhibition of aggregation. However this may be $\vec{F}$ the present findings support the inference fromf? electron microscopy that platelet mucopoly은 saccharide is involved in platelet stickiness․ㅡㄴ (Behnke, 1968; Nakao and Angrist, 1968 Shirasawa and Chandler, 1969; French, Adams $\mathbb{Q}$ and Sheppard, 1970; White, 1970).

I thank T. N. Madgwick, BSc, and M. D黑 Etherington, BSc, for technical assistance, and the Wellcome Trust for a grant.

\section{References}

Achard, Ch., and Aynand, M. (1909). Le globulin. Sem. méd? (Paris), 29, 169-174.

Behnke, O. (1968). Electron-microscopical observations on th surface coating of human platelets. J. Ultrastruct. Res. $\mathbb{D}$ 24, 51-69.

French, J. E., Adams, E. P., and Sheppard, U. (1970). The surface coat (glycocalyx) of bovine blood platelets. In Platelets and the Vessel Wall, edited by G. Schettler. Thieme, Stuttgare (in the press).

Luft, J. (1966). Fine structure of capillary and endo-capillary $\vec{e}$ layer as revealed by ruthenium red. Fed. Proc., 25, 1773-O 1783.

Muir, H., and Mustard, J. F. (1967). Enhancement of platele aggregation by glycosaminoglycans (mucopolysaccharides) Colloques Internationaux du Centre Nationale de la Recherche Scientifique, No. 169, p. 589-596.

Nakao, K., and Angrist, A. A. (1968). Membrane surface specialn isation of blood platelet and megakaryocyte. Nature (Lond.), 217, 960-961.

O'Brien, J. R., Heywood, J. B., and Heady, J. A. (1966). The quantitation of platelet aggregation induced by fouro compounds: a study in relation to myocardial infarction 3 Thrombos. Diathes. haemorrh. (Stuttg.), 16, 752-767.

O'Brien, J. R., Finch, W., and Clark, E. (1970). Platelet-bound and soluble platelet factor 4 : effects of aggregating agents, of aggregation and of aspirin. Proc. Soc. exp. Biol. (N.Y.) 134, 1128-1131.

Scott, J. E., and Willett, I. H. (1966). Binding of cationic dyes to nucleic acids and other biological polyanions. Nature
(Lond.), 209, 985-987.

Seaman, G. V. F., and Vassar, P. S. (1966). Changes in the electrokinetic properties of platelets during their aggregation
Arch. Biochem., 117, 10-17.

Shirasawa, K., and Chandler, A. B. (1969). Fine structure of theO bond between the platelets in artificial thrombi and in platelet aggregates induced by adenosine diphosphate Amer. J. Path., 57, 127-152.

Tice, L. W., and Barrnett, R. J. (1965). The diazophthalocyanins as reagents for fine structural cytochemistry. J. Cell Biol. O
$25,23-41$.

Walton, K. W., and Ricketts, C. R. (1954). Investigation of theN histochemical basis of metachromasia. Brit. J. exp. Path. N
35, 227-240.

White, J. G. (1970). The inter-platelet zone. Amer. J. Path., 58, ర 19-29. 